\title{
Altered Immunomodulation by Glucocorticoids in Neonatal Pigs Exposed to a Psychosocial Stressor
}

\author{
MARGRET TUCHSCHERER, ELLEN KANITZ, BIRGER PUPPE, AND ARMIN TUCHSCHERER
}

Research Unit Behavioural Physiology [M.T., E.K., B.P.], Research Unit Genetics and Biometry [A.T.], Leibniz Institute for Farm Animal Biology, Dummerstorf D-18196, Germany

\begin{abstract}
Stressful early life experiences can have short- and long-term effects on neuroendocrine and immune mechanisms of adaptation, which are primarily modulated by glucocorticoids. This study aimed to examine how the stress and immune systems interact to cope with psychosocial stress induced by a single social isolation (4 h) in neonatal pigs at 7, 21, or $35 \mathrm{~d}$ of age. This social isolation provoked increased plasma ACTH and cortisol concentrations and reduced TNF- $\alpha$ levels but had no significant effect on IL-6 levels. Socially isolated piglets had a higher lipopolysaccharide (LPS)-stimulated proliferative response of peripheral blood mononuclear cells (PBMCs) than controls, whereas concanavalin A (ConA)-induced proliferation was not affected by isolation. A single social isolation also induced a dose-dependent cortisol resistance in ConA- and LPS-stimulated PBMCs compared with controls, which may be an adaptive response in the short term. Moreover, LPS-stimulated cultures from control piglets showed a reduction in cortisol sensitivity with increasing age. Conclusively, these findings provide stress-related measures for the psychophysiological assessment of livestock handling practices but might also have implications for stress and health studies in young animals and humans. (Pediatr Res 68: 473-478, 2010)
\end{abstract}

$\mathrm{G}$ lucocorticoids (GC), the final mediators of hypothalamicpituitary-adrenal (HPA) activation, are important regulators of various physiological systems, including the immune system, and play a major role in the adaptation of organisms to stressful situations. Previous studies in humans and animals have shown that circulating GCs are beneficial during the adaptive process in the short run, but during long-term or repeated exposure to stressors, the effects of GCs on immune function are detrimental $(1,2)$.

Furthermore, it is well known that there are crucial interactive loops between GCs and cytokines. Proinflammatory cytokines, produced by activated immune cells, are potent activators of the HPA axis. GCs in turn suppress cytokine production and, by this mechanism, are able to terminate immune processes to protect the organism from an overactive immune system $(3,4)$. An increasing number of studies suggest that GCs may cause alterations in cytokine production, which favor humoral immune responses while suppressing cellular immunity $(5,6)$. Although this model of immune deviation could be an adaptive mechanism to prevent the immune response from causing tissue damage, maladaptive

Received April 7, 2010; accepted July 17, 2010.

Correspondence: Margret Tuchscherer, Ph.D., Research Unit Behavioural Physiology, Leibniz Institute for Farm Animal Biology, Wilhelm-Stahl-Allee 2, D-18196 Dummerstorf, Germany; e-mail: mtuchsch@fbn-dummerstorf.de

Supported by a grant from the Deutsche Forschungsgemeinschaft Project: Ka 1266/4-1. responses to stress-induced immune alterations may contribute to increased disease susceptibility (7).

In addition to peripheral GC levels, the GC sensitivity of different target cells from organisms exposed to stressors should also be considered when evaluating adaptive processes, potential imbalances, and increased health risks $(3,4)$. Several studies have supported the hypothesis that social stressors affect the steroid sensitivity of immune cells in animals and humans. As shown in mice, repeated social disruption stress may cause reduced GC sensitivity in splenocytes $(8-10)$. In addition, the corticosteroid sensitivity of peripheral blood lymphocytes was decreased in chronically stressed caregivers of patients with dementia (11).

However, acute modulation of GC sensitivity in response to short-term psychosocial stress has only been investigated in a small number of studies. In students, it has been demonstrated that stress associated with academic examinations provokes an activation of the HPA axis with increased levels of cortisol followed by a transient decrease in the GC sensitivity of leukocytes ex vivo (12). Similarly, the laboratory Trier Social Stress Test induced changes in GC sensitivity for proinflammatory cytokine production by lipopolysaccharide (LPS)stimulated whole blood cultures of healthy humans $(4,13)$. Moreover, there is also evidence for age-related changes in GC sensitivity of different target tissues in human and animal models, with greater sensitivity observed in younger individuals $(14,15)$.

Psychosocial stress in early life, such as social deprivation and maternal separation, has been shown to induce robust alterations in the physiological mechanisms of adaptation. In humans, early life stress is viewed as a major risk factor for the development of mental disorders $(15,16)$ and immunerelated diseases in later life (17). Although the importance of psychosocial factors for offspring development is well established, limited information exists about how the immune and stress systems interact to cope with psychosocial stressors in early postnatal life.

Recent findings from our group indicate that social isolation of piglets reliably activates the release of stress hormones and causes changes in the proportions of blood lymphocytes, reflecting also the negative emotions experienced by this

\footnotetext{
Abbreviations: ConA, concanavalin A; GC, glucocorticoids; GR, glucocorticoid receptor; HPA, hypothalamic-pituitary-adrenal; LPS, lipopolysaccharide; PBMCs, peripheral blood mononuclear cells
} 
treatment $(18,19)$. In contrast to rodents, the pig HPA axis is well developed and functional at birth (20). Therefore, this social isolation model in pigs may be useful for studying the effects of psychosocial stress on the responsiveness of the immune-neuroendocrine system early in life. Based on our previous research, we hypothesized that social stress in neonatal pigs alters circulating levels of cytokines and also affects the GC sensitivity of peripheral immune cells. To test this hypothesis, we examined the effects of an activated HPA axis in piglets exposed to a single social isolation for $4 \mathrm{~h}$ at different age categories on cytokines. Plasma concentrations of stress hormones (ACTH and cortisol) and proinflammatory cytokines (TNF- $\alpha$ and IL-6) were analyzed. Furthermore, the reactivity of cells of the immune system and the sensitivity of these cells to GC inhibition were assessed by measuring the in vitro proliferation of peripheral blood mononuclear cells (PBMCs) in response to the T-cell mitogen ConA and the B-cell mitogen LPS under a range of increasing cortisol concentrations.

\section{METHODS}

Animals and experimental design. The procedures involving animal treatments were approved by the Committee on Animal Care and Use of the Agricultural Department of Mecklenburg-Vorpommern, Germany. Piglets were taken from eight German Landrace litters that were born and raised in the experimental pig unit of our institute. After birth, the litter size was standardized to 10 piglets. During the suckling period, sows and their piglets were housed in a loose farrowing pen $\left(6 \mathrm{~m}^{2}\right)$ at a room temperature of $28 \pm$ $1^{\circ} \mathrm{C}$. At 7,21 , or $35 \mathrm{~d}$ of age, two piglets from each litter were randomly allocated to an isolation treatment or to a nonisolated control group. The allocation of male and female piglets within both groups was approximately equivalent. The piglets were isolated once from their mother and siblings in a separate test room located in the same experimental station for $4 \mathrm{~h}$ in the morning $(0700-1100 \mathrm{~h})$. Each piglet was placed alone into an opaque plastic box $(68 \times 50 \times 65 \mathrm{~cm})$ with sawdust on the floor, adequate air passage, and temperature control $\left(28 \pm 1^{\circ} \mathrm{C}\right)$. The control piglets remained undisturbed in the farrowing pen during this time. Blood samples were taken while piglets were in a supine position by anterior vena cava puncture (the whole procedure lasted $\sim 30 \mathrm{~s}$ ) from both isolated ( $n=8$ per age group) and nonisolated control piglets ( $n=8$ per age group) both before, for basal levels of stress hormones, and immediately after the social isolation. One aliquot of EDTA blood samples was centrifuged at $2000 \times g$ for $15 \mathrm{~min}$ at $4^{\circ} \mathrm{C}$ to separate plasma, which was stored at $-20^{\circ} \mathrm{C}$ until analysis of ACTH, cortisol, TNF- $\alpha$, and IL-6. Another aliquot of heparinized blood samples was stored on ice until processing for immunological measurements.

Hormone analyses. The analyses of ACTH concentrations were performed in duplicate on $200 \mu \mathrm{L}$ plasma using a commercial ${ }^{125}$ I-RIA kit (DSL, Inc., Sinsheim, Germany) according to the instructions of the manufacturer. The lowest level of ACTH that could be detected by this assay was $3.5 \mathrm{pg} / \mathrm{mL}$, and intra- and interassay coefficients of variation were 6.9 and $9.6 \%$, respectively. Plasma cortisol concentrations were analyzed in duplicates using a commercially available ${ }^{125}$ I-RIA kit (DSL, Inc.) according to the manufacturer's instructions. The test sensitivity was $8.1 \mathrm{nmol} / \mathrm{L}$, and intra- and interassay coefficients of variation were 8.2 and $9.8 \%$, respectively. The ratio of ACTH/cortisol (A/C) was calculated. Both assays were validated for porcine plasma.

Measurement of mitogenic response and cortisol sensitivity. The mitogens ConA $(5 \mu \mathrm{g} / \mathrm{mL})$ and LPS $(10 \mu \mathrm{g} / \mathrm{mL})$ were used in a lymphocyte proliferation/viability assay as previously described (19). Briefly, PBMCs were isolated from heparinized blood by density gradient centrifugation, and the cell concentration was adjusted to $5 \times 10^{6}$ cells $/ \mathrm{mL}$ complete RPMI 1640 medium. To test the sensitivity of cells to inhibition by GCs, aliquots from each cell suspension were treated with increasing concentrations of cortisol $(0,0.05,0.1,0.5$, and $1 \mu \mathrm{M})$ diluted in a buffer of $0.2 \%$ ethanol in complete medium. All reagents were obtained from Sigma Chemical Co. (St. Louis, MO). Cell suspensions were added in triplicate to flat-bottom 96-well plates at a volume of $200 \mu \mathrm{L} / w e l l$, and plates were incubated for $72 \mathrm{~h}$ in a $5 \%$ $\mathrm{CO}_{2}$-humidified incubator at $37^{\circ} \mathrm{C}$. Cell proliferation/viability was evaluated using 3-[4,5-dimethyldiazol-2-yl]-2,5 diphenyl tetrazolium bromide (MTT) assay (Roche Diagnostics, Mannheim, Germany). The OD was measured by a microplate reader (Dynatech, Denkendorf, Germany) using a test wavelength of $550 \mathrm{~nm}$ and a reference wavelength of $690 \mathrm{~nm}$. The results were expressed as mitogen-stimulated proliferation (OD in the presence of mitogen subtracted by OD in the absence of mitogen) and as cortisol resistance index, which was calculated as the OD for a culture treated with cortisol divided by the OD for cells from the same group not treated with cortisol $\times 100$ as described by Stark et al. (8).

Cytokine assays. TNF- $\alpha$ and IL- 6 concentrations were analyzed in plasma samples using commercially available pig ELISA kits (DRG Instruments $\mathrm{GmbH}$, Marburg, Germany) according to the manufacturer's instructions. Samples were analyzed in duplicate at a 1:2 dilution. The sensitivity of the TNF- $\alpha$ assay was $6 \mathrm{pg} / \mathrm{mL}$ and intra- and interassay coefficients of variation were 6.2 and $8.2 \%$, respectively. The limit of detection of the IL- 6 assay was $45 \mathrm{pg} / \mathrm{mL}$. Intra- and interassay coefficients of variation were 4.5 and $9.8 \%$, respectively.

Statistical analysis. Statistical analyses were performed using the SAS System for Windows, release 9.2 (21). Data were evaluated by ANOVA using the MIXED procedure. The model included the fixed classification variables social isolation (isolation and control), age (d 7, 21, and 35), sex (male and female), the interaction age $\times$ isolation, and the random sow effect. The ANOVA model for the cortisol resistance index contained the fixed effects social isolation (isolation and control), age (d 7, 21, and 35), and mitogen (ConA and LPS) and the repeated factor cortisol concentration with measures at four levels $(0.05,0.1,0.5$, and $1 \mu \mathrm{M})$ using an unstructured residual covariance matrix and the random sow effect, and all interactions between the fixed effects. In addition, least-squares means (LS-means) and SE were computed for each effect in the models. Significance of differences between LS-means was tested by the Tukey-Kramer procedure $(p<0.05)$.

\section{RESULTS}

Plasma hormones and cytokines. Before the social isolation on $\mathrm{d} 7,21$, and 35, there were no significant differences in plasma ACTH and cortisol concentrations observed between control piglets and those that would be isolated $(p>0.89$, data not shown).

ACTH (Fig. 1A), cortisol (Fig. 1B), and TNF- $\alpha$ (Fig. 2A) concentrations were affected by social isolation $(p<0.01)$, whereas IL- 6 concentrations were not influenced by isolation ( $p=0.23$; Fig. 2B). Pair-wise comparisons of the LS-means of isolated and control piglets indicated a significantly higher ACTH concentration on $\mathrm{d} 35(p<0.05)$ and significantly higher cortisol concentrations on $\mathrm{d} 7(p<0.05)$ and $21(p<$ 0.05 ) in isolated animals (Fig. 1). As shown in Fig. $2 A$, the TNF- $\alpha$ concentration in plasma from isolated piglets was significantly lower compared with controls on d 7 ( $p<0.05)$.

Mitogenic response and cortisol sensitivity. There was no effect of social isolation on the proliferation of PBMCs in
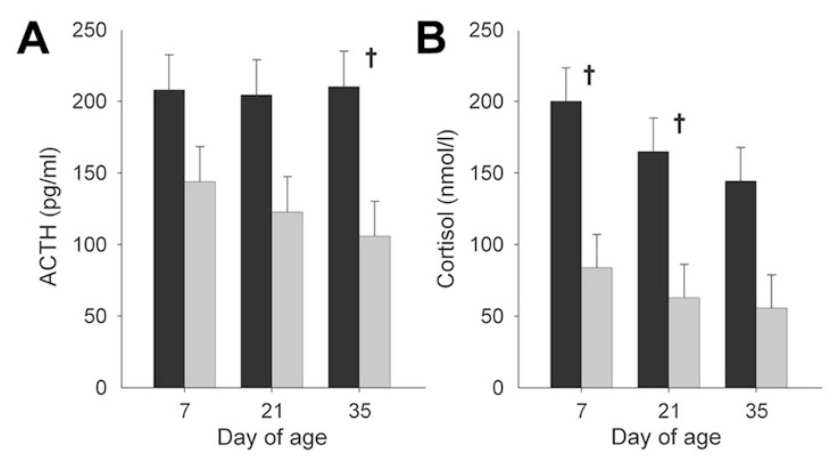

Figure 1. Plasma ACTH $(A)$ and cortisol $(B)$ concentrations in isolated ( $n=8$ at each age) and control piglets $(\square ; n=8$ at each age) after social isolation of $4 \mathrm{~h}$ on $\mathrm{d} 7,21$, and 35. Data are expressed as LS-means + SE. Significant differences between isolated and control piglets are indicated by a dagger $(\dagger p<0.05)$. 

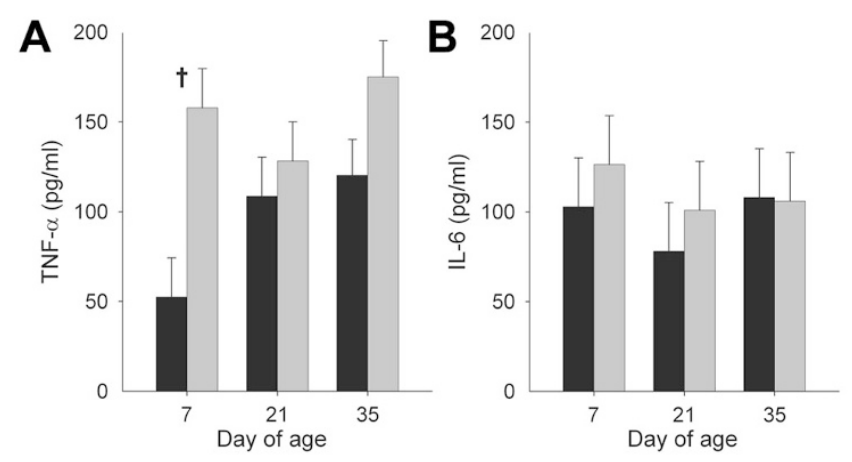

Figure 2. Plasma TNF- $\alpha(A)$ and IL-6 $(B)$ concentrations in isolated $(\square ; n=$ 8 at each age) and control piglets $(\square ; n=8$ at each age) after social isolation of $4 \mathrm{~h}$ on d 7, 21, and 35. Data are expressed as LS-means + SE. Significant differences between isolated and control piglets are indicated by a dagger $(\dagger p<0.05)$.

response to ConA ( $p=0.455)$. In contrast, the response to LPS was influenced by isolation $(p<0.001)$. As shown in Table 1, LPS-stimulated proliferation was significantly higher in isolated piglets compared with controls on $\mathrm{d} 21(p<0.05)$ and $35(p<0.01)$. In addition, the factor age had an effect on mitogen-induced PBMC proliferation in response to both ConA and LPS $(p<0.0001)$. Sensitivity of PBMCs to increasing cortisol concentrations, expressed as resistance indices (\%), was assessed in cultures stimulated with ConA (Fig. 3) or LPS (Fig. 4). Repeated-measures ANOVA indicated that the sensitivity of PBMCs from piglets to cortisol was affected by social isolation $(p<0.001)$, concentration of cortisol $(p<0.001)$, type of mitogen $(p<0.05)$, and age of the piglets $(p<0.001)$. Furthermore, significant interactions of social isolation $\times$ age $(p<0.01)$, cortisol concentration $\times$ mitogen $(p<0.001)$, and mitogen $\times$ age $(p<0.01)$ were found. ConA-stimulated PBMCs from isolated piglets showed significantly less inhibition by all cortisol concentrations than cells from control piglets on d 7 (Fig. 3A), 21 (Fig. 3B), and 35 (Fig. $3 C$; in all cases, $p<0.001$ ). LPS-induced stimulation of PBMCs from isolated piglets on $\mathrm{d} 7$ of age was also significantly less inhibited by cortisol at all concentrations ( $p<0.001$; Fig. 4A), whereas on d 21, PBMCs from isolated piglets seemed to be more resistant to cortisol only at $0.5 \mu \mathrm{M}$ $(p<0.01)$ and $1 \mu \mathrm{M}(p<0.01$; Fig. $4 B)$. However, there was no difference in resistance of LPS-stimulated cultures to cortisol between isolated and control piglets on d 35 ( $p>0.56$; Fig. 4C). Furthermore, a dose-dependent decrease of cortisol resistance was found in ConA-stimulated cultures from both isolated and control piglets at 7, 21, and $35 \mathrm{~d}$ of age $(p<0.01$; Fig. $3 A-C$ ) and, in LPS-stimulated PBMCs, only from control piglets on d 7 ( $p<0.02$, Fig. 4A). Pair-wise comparisons of resistance indices between ConA- and LPS-stimulated PBMCs from isolated piglets indicated that ConA-induced cells seemed to be more resistant to cortisol than LPSstimulated cells at $0.05 \mu \mathrm{M}$ cortisol concentration on $\mathrm{d} 21$ $(92.4 \pm 1.2$ versus $85.2 \pm 1.5 \%, p=0.004$, Figs. $3 B$ and $4 B)$ and 35 (95.8 \pm 1.2 versus $88.8 \pm 1.5 \%, p=0.008$, Figs. $3 C$ and $4 C$ ). However, in control piglets, ConA-stimulated PBMCs showed a lower cortisol resistance than LPSstimulated cultures only at the highest cortisol concentration on d $35(62.9 \pm 1.8$ versus $80.3 \pm 1.9 \%, p<0.001$, Figs. $3 C$ and $4 C$ ). Cortisol resistance did not differ among the three age categories, in ConA-stimulated cultures from isolated and control piglets $(p>0.92)$ or in LPS-stimulated cultures from isolated piglets $(p>0.81)$. In contrast, resistance to cortisol in LPS-stimulated cultures from control piglets was significantly lower on d 7 (Fig. 4A) compared with d 35 (Fig. 4C) at 0.1, 0.5 , and $1 \mu \mathrm{M}$ cortisol $(70.9 \pm 2.2$ versus $82.5 \pm 2.2 \%, p<$ $0.02 ; 67.2 \pm 1.9$ versus $77.7 \pm 1.9 \%, p<0.01 ; 62.8 \pm 1.9$ versus $80.3 \pm 1.9 \%, p<0.001$, respectively) and on $\mathrm{d} 21$ (Fig. 4B) compared with d 35 (Fig. 4C) at 0.5 and $1 \mu \mathrm{M}$ cortisol $(68.5 \pm 1.9$ versus $77.7 \pm 1.9 \%, p<0.05 ; 68.4 \pm 1.9$ versus $80.3 \pm 1.9 \%, p<0.01$, respectively). The factor sex had no significant effect on any of the traits investigated $(p>$ 0.29 ; data not shown).

\section{DISCUSSION}

There are numerous challenges within a domestic piglet's environment such as handling by humans and abrupt weaning that involve psychosocial factors, which may play critical role in adaptive responses of the neuroendocrine and immune systems. In this study, a single exposure to social isolation for $4 \mathrm{~h}$ was perceived as a stressful condition by piglets at each of the three age categories. This was indicated by increased plasma ACTH and cortisol levels, which confirm that social isolation is a robust paradigm of psychosocial stress in pigs (22,23).

Furthermore, a single social isolation stress in our experiments resulted in lower plasma TNF- $\alpha$ levels but had no significant effect on IL-6 levels. Recent findings in animal and human research suggest that short-term psychological stress may alter the circulating levels of inflammatory cytokines $(24,25)$. TNF- $\alpha$ is an important proinflammatory cytokine that regulates inflammatory responses to infection and stress and activates the HPA axis. GCs in turn act as a negative feedback regulator and suppress further release of proinflammatory cytokines, thereby protecting against overstimulation of the

Table 1. ConA- and LPS-stimulated proliferation of PBMCs in isolated and control piglets after social isolation on d 7, 21, and 35

\begin{tabular}{|c|c|c|c|c|c|c|}
\hline \multirow[b]{2}{*}{ Proliferation } & \multicolumn{2}{|c|}{ D 7} & \multicolumn{2}{|c|}{ D 21} & \multicolumn{2}{|c|}{ D 35} \\
\hline & Isolated & Control & Isolated & Control & Isolated & Control \\
\hline ConA (OD) & $0.679 \pm 0.0222$ & $0.718 \pm 0.0222$ & $0.584 \pm 0.0224$ & $0.576 \pm 0.0224$ & $0.859 \pm 0.0224$ & $0.868 \pm 0.0222$ \\
\hline LPS (OD) & $0.363 \pm 0.0157$ & $0.303 \pm 0.0157$ & $0.302 \pm 0.0160^{*}$ & $0.227 \pm 0.0160$ & $0.322 \pm 0.0160 \dagger$ & $0.225 \pm 0.0157$ \\
\hline
\end{tabular}

Data are expressed as LS-means \pm SE ( $n=8$ per group and day of age).

OD was significantly higher in isolated piglets in comparison with control piglets.

$* p<0.05$.

$\dagger p<0.01$. 

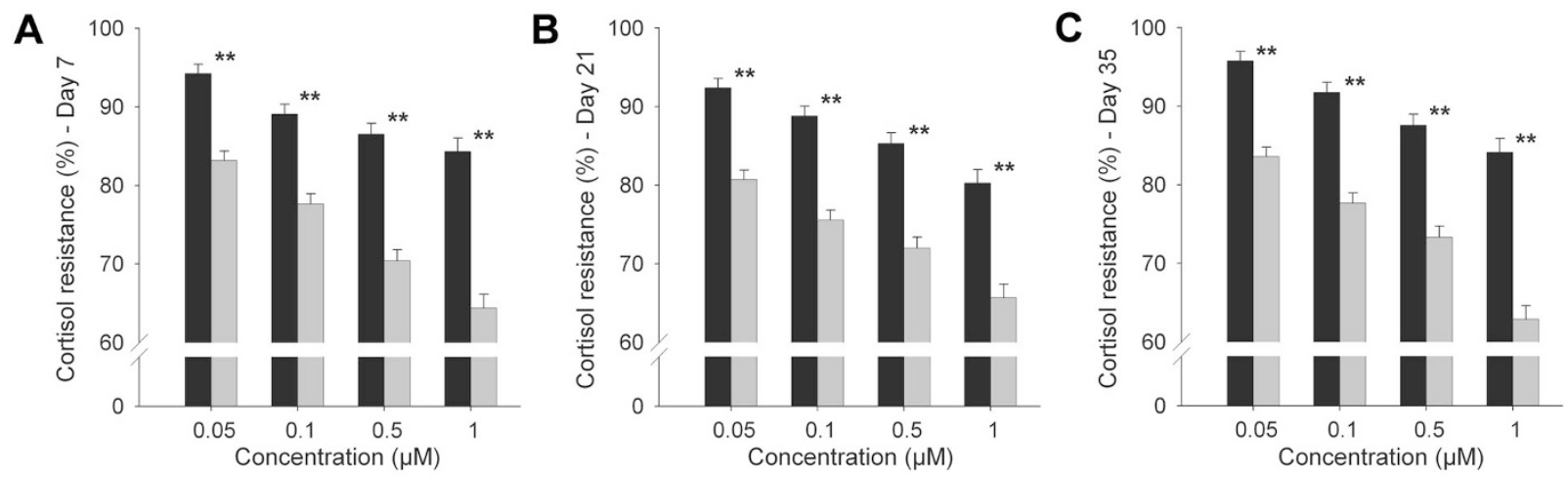

Figure 3. Cortisol resistance index (\%) of ConA-stimulated PBMCs cultured with increasing cortisol concentrations $(0.05,0.1,0.5$, and $1 \mu \mathrm{M})$ for isolated $(\square$; $n=8$ at each age) and control piglets $(\square ; n=8$ at each age) after social isolation of $4 \mathrm{~h}$ on $\mathrm{d} 7(A), 21(B)$, and 35 (C). The index was calculated as the OD for a culture treated with cortisol divided by the OD for cells from the same group not treated with cortisol $\times 100$. Data are expressed as LS-means + SE. Significant differences between isolated and control piglets are indicated by asterisks $(* * p<0.001)$.
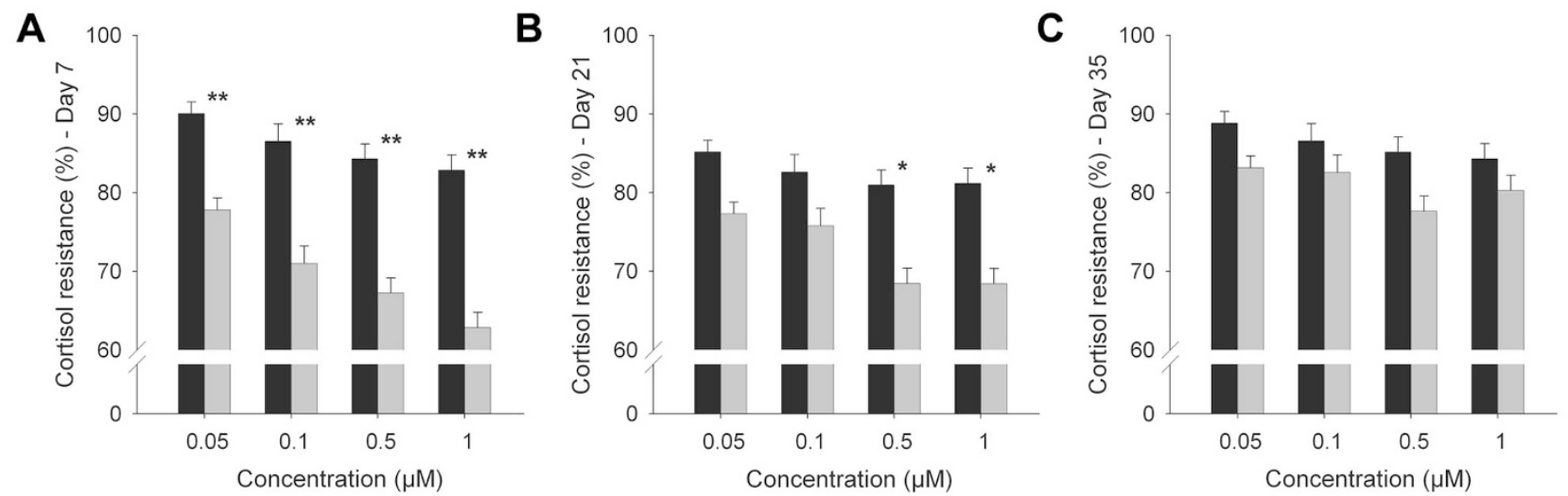

Figure 4. Cortisol resistance index (\%) of LPS-stimulated PBMCs cultured with increasing cortisol concentrations $(0.05,0.1,0.5$, and $1 \mu \mathrm{M})$ for isolated $(\mathbf{\square}$; $n=8$ at each age) and control piglets $(\square ; n=8$ at each age) after social isolation of $4 \mathrm{~h}$ on $\mathrm{d} 7(A), 21(B)$, and 35 (C). The index was calculated as the OD for a culture treated with cortisol divided by the OD for cells from the same group not treated with cortisol $\times 100$. Data are expressed as LS-means + SE. Significant differences between isolated and control piglets are indicated by asterisks $\left(* p<0.01\right.$ and $\left.*^{*} p<0.001\right)$.

immune system $(3,4)$. Therefore, we suppose that the increased cortisol levels in socially isolated piglets are responsible for the lower TNF- $\alpha$ levels of these animals.

Several reports have shown that repeated or chronic activation of the HPA axis can cause increased systemic GC levels and may lead to altered activation and diminished GC responsiveness of immune cells resulting in excessive inflammatory responses and increased health risks $(8,9,11)$. In our study, the consequences of short-term psychosocial stress on cell proliferation and GC sensitivity of T lymphocytes were investigated by stimulating PBMCs with ConA (26), and LPS was used for stimulation of B cells and monocytes (27). We found that social isolation had no effect on lymphocyte proliferation in response to ConA, whereas in vitro LPS-induced cell proliferation was increased in isolated piglets. Our results support previous findings in which mice exposed to social disruption demonstrated enhanced proliferation of LPSstimulated splenocytes $(8,10,28)$. In addition, our data suggest that short-term social stress promotes humoral immune responses. In this study, the mechanism underlying the different effects of isolation stress on modulation of ConA- and LPSstimulated proliferation responses were not examined. However, animal studies suggest that those effects could be medi- ated by altered glucocorticoid receptor (GR) expression and/or function (29). For example, ligand-induced GR downregulation is a significant mechanism to inhibit GC signaling in various tissues and cell types but not in T lymphocytes (30).

An in vitro cortisol sensitivity assay showed that ConA- and LPS-stimulated PBMCs from socially isolated piglets were less sensitive to the inhibitory effects of cortisol, even in the presence of high concentrations. To our knowledge, this is the first study to demonstrate that a short-term psychosocial stress may induce cortisol resistance in PBMC cultures from neonates. Similarly, GC resistance of blood immune cells has been reported after a single physical exercise (3) or mental stress in humans $(4,12,13)$. However, most previous work using socially defeated mice has shown decreased GC sensitivity of spleen cells, which was more pronounced in animals with higher number of injuries because of fighting $(8,9)$. In particular, a study from Merlot et al. (10) reported that wounded and nonwounded mice presented similar responses to social stress. In general, development of GC resistance after repeated or chronic stress is viewed as maladaptive if the resistant individual has a predisposition to an autoimmune disease or is exposed to an infectious challenge but it may be also adaptive for healing wounds and protection against bacterial contamination $(8,28,31)$. The effects of GC resistance 
may be different depending on the nature and timing of the stressor and the individual state of the organism (32). Therefore, the rapid development of cortisol resistance observed in the present isolation model could be adaptive for the organism to preserve cell function and prepare the immune system for potential unpredictable danger. However, identification of the mechanisms mediating such a rapid modulation of GC sensitivity and their possible consequences remains to be investigated.

Although in our study, LPS-stimulated cells from isolated piglets showed higher cell proliferation compared with controls on d 21 and 35, we found that these cells were more sensitive to inhibition by minimal cortisol concentrations than ConA-stimulated cell cultures. Similarly, in academically stressed students, there was a positive correlation between the degree of lymphocyte activation and cortisol inhibition in vitro (12). It has been suggested that GC sensitivity of lymphocytes varies with the state of immunological activation of the cells and can be modulated by the GR number or expression level in the cells (33) and by the hormone binding affinity of the GR (4).

LPS-stimulated PBMCs of younger control piglets were much more sensitive to inhibition of the proliferative response by cortisol than cells of piglets at $35 \mathrm{~d}$ of age. This finding confirms an age-dependent effect, because it was documented that neonatal lymphocytes are more sensitive to GC inhibition than are those from older pigs (15). In human infants and children, a decreasing GC sensitivity with advancing age has also been shown (14). In both human and pigs, the immune system is not fully developed at birth $(34,35)$. Therefore, age-related changes in GC sensitivity may be related to a still functionally immature immune system. It is known that sudden separation of suckling piglets from the mother at an early age impairs antibody-mediated immunity (36), which may be partially explained by an increased sensitivity of neonatal lymphocytes to GC inhibition (15). Hence, with respect to the present results, an increasing weaning age could be associated with enhanced protection of piglets against frequently occurring bacterial infections of the gastrointestinal and respiratory tracts provoked by stressful experiences after weaning.

Recently, we have demonstrated that repeated social isolation of neonatal pigs may cause long-term changes in neuroendocrine and immune regulation and can modulate coping mechanisms against a later risk of infection (2,23). A single exposure to social stress in rodents has been found to induce short-term effects on immune responses (37) and long-term consequences on behavior, HPA responsiveness, and immune functions $(17,38)$. Therefore, future studies are needed to investigate whether a single social isolation of piglets during the early neonatal period can also modify sensitivity to stress and infection later in life.

In summary, this study shows that a single exposure to isolation stress in piglets causes activation of the HPA axis and suppression of circulating TNF- $\alpha$. Furthermore, isolation induces a state of cortisol resistance in blood immune cells, which may be an adaptive advantage to maintain cellular immune responses in the short term. These results extend previous findings about acute modulation of GC sensitivity in immune tissue after psychological stress. This may have implications for the assessment of mental experiences in young animals and humans.

Acknowledgments. We thank the staff of the Research Unit of Behavioural Physiology for their technical assistance and Ulrike Gimsa for the valuable comments on the article.

\section{REFERENCES}

1. Sorrells SF, Sapolsky RM 2007 An inflammatory review of glucocorticoid actions in the CNS. Brain Behav Immun 21:259-272

2. Tuchscherer M, Kanitz E, Puppe B, Tuchscherer A 2006 Early social isolation alters behavioural and physiological responses to an endotoxin challenge in piglets. Horm Behav 50:753-761

3. DeRijk R, Michelson D, Karp B, Petrides J, Galliven E, Deuster P, Paciotti G, Gold PW, Sternberg EM 1997 Exercise and circadian rhythm-induced variations in plasma cortisol differentially regulate interleukin-1 $\beta$ (IL-1 $\beta$ ), IL-6, and tumor necrosis factor- $\alpha(\mathrm{TNF} \alpha)$ production in humans: high sensitivity of $\mathrm{TNF} \alpha$ and resistance of IL-6. J Clin Endocrinol Metab 82:2182-2191

4. Rohleder N, Wolf JM, Kirschbaum C 2003 Glucocorticoid sensitivity in humansinterindividual differences and acute stress-effects. Stress 6:207-222

5. Elenkov IJ 2004 Glucocorticoids and the Th1/Th2 balance. Ann N Y Acad Sci 1024:138-146

6. Webster Marketon JI, Glaser R 2008 Stress hormones and immune function. Cell Immunol 252:16-26

7. Salicrú AN, Sams CF, Marshall GD 2007 Cooperative effects of corticosteroids and catecholamines upon immune deviation of the type-1/type- 2 cytokine balance in favour of type-2 expression in human peripheral blood mononuclear cells. Brain Behav Immun 21:913-920

8. Stark JL, Avitsur R, Padgett DA, Campbell KA, Beck FM, Sheridan JF 2001 Socia stress induces glucocorticoid resistance in macrophages. Am J Physiol Regul Integr Comp Physiol 280:R1799-R1805

9. Avitsur R, Stark JL, Sheridan JF 2001 Social stress induces glucocorticoid resistance in subordinate animals. Horm Behav 39:247-257

10. Merlot E, Moze E, Dantzer R, Neveu PJ 2004 Cytokine production by spleen cells after social defeat in mice: activation of $\mathrm{T}$ cells and reduced inhibition by glucocorticoids. Stress 7:55-61

11. Bauer ME, Vedhara K, Perks P, Wilcock GK, Lightman SL, Shanks N 2000 Chronic stress in caregivers of dementia patients is associated with reduced lymphocyte sensitivity to glucocorticoids. J Neuroimmunol 103:84-92

12. Sauer J, Polack E, Wikinski S, Holsboer F, Stalla GK, Arzt E 1995 The glucocorticoid sensitivity of lymphocytes changes according to the activity of the hypothalamic-pituitary-adrenocortical system. Psychoneuroendocrinology 20:269-280

13. Rohleder N, Schommer NC, Hellhammer DH, Engel R, Kirschbaum C 2001 Sex differences in glucocorticoid sensitivity of proinflammatory cytokine production after psychosocial stress. Psychosom Med 63:966-972

14. Kavelaars A, Zijlstra J, Bakker JM, van Rees EP, Visser GH, Zegers BJ, Heijnen CJ 1995 Increased dexamethasone sensitivity of neonatal leukocytes: different mechanisms of glucocorticoid inhibition of T cell proliferation in adult and neonatal cells. Eur J Immunol 25:1346-1351

15. Yang WC, Schultz RD 1986 Effects of corticosteroid on porcine leukocytes: age-related effects of corticosteroid inhibition on porcine lymphocyte responses to mitogens. Vet Immunol Immunopathol 13:19-29

16. Veenema AH 2009 Early life stress, the development of aggression and neuroendocrine and neurobiological correlates: what can we learn from animal models? Front Neuroendocrinol 30:497-518

17. Bellinger DL, Lubahn C, Lorton D 2008 Maternal and early life stress effects on immune function: relevance to immunotoxicology. J Immunotoxicol 5:419-444

18. Kanitz E, Puppe B, Tuchscherer M, Heberer M, Viergutz T, Tuchscherer A 2009 A single exposure to social isolation in domestic piglets activates behavioural arousal, neuroendocrine stress hormones, and stress-related gene expression in the brain Physiol Behav 98:176-185

19. Tuchscherer M, Kanitz E, Puppe B, Tuchscherer A, Viergutz T 2009 Changes in endocrine and immune responses of neonatal pigs exposed to a psychosocial stressor. Res Vet Sci 87:380-388

20. Klemcke HG, Pond WG 1991 Porcine adrenal adrenocorticotropic hormone receptors: characterization, changes during neonatal development, and response to a stressor. Endocrinology 128:2476-2488

21. SAS Institute Inc 2008 SAS/STAT 9.2 User's Guide. SAS Institute Inc, Cary, NC

22. Ruis MA, te Brake JH, Engel B, Buist WG, Blokhuis HJ, Koolhaas JM 2001 Adaptation to social isolation acute and long-term stress responses of growing gilts with different coping characteristics. Physiol Behav 73:541-551

23. Kanitz E, Tuchscherer M, Puppe B, Tuchscherer A, Stabenow B 2004 Consequences of repeated early isolation in domestic piglets (Sus scrofa) on their behavioural, neuroendocrine, and immunological responses. Brain Behav Immun 18:35-45

24. LeMay LG, Vander AJ, Kluger MJ 1990 The effects of psychological stress on plasma interleukin-6 activity in rats. Physiol Behav 47:957-961

25. Steptoe A, Hamer M, Chida Y 2007 The effects of acute psychological stress on circulating inflammatory factors in humans: a review and meta-analysis. Brain Behav Immun 21:901-912

26. Dorn AD, Waters WR, Byers VM, Pesch BA, Wannemuehler MJ 2002 Characterization of mitogen-stimulated porcine lymphocytes using a stable fluorescent dye (PKH2) and multicolour flow cytometry. Vet Immunol Immunopathol 87:1-10 
27. Griffiths M, Keast D 1990 The effects of glutamine on murine splenic leukocyte responses to T an B cell mitogens. Immunol Cell Biol 68:405-408

28. Bailey MT, Kinsey SG, Padgett DA, Sheridan JF, Leblebicioglu B 2009 Social stress enhances IL- $1 \beta$ and TNF- $\alpha$ production by Porphyromonas gingivalis lipopolysaccharide-stimulated CD-11+ cells. Physiol Behav 98:351-358

29. Haczku A, Panettieri RA 2010 Social stress and asthma: the role of corticosteroid insensitivity. J Allergy Clin Immunol 125:550-558

30. Schaaf MJ, Cidlowski JA 2002 Molecular mechanisms of glucocorticoid action and resistance. J Steroid Biochem Mol Biol 83:37-48

31. Avitsur R, Stark JL, Dhabhar FS, Sheridan JF 2002 Social stress alters splenocyte phenotype and function. J Neuroimmunol 132:66-71

32. Avitsur R, Poeell N, Padgett DA, Sheridan JF 2009 Social interactions, stress, and immunity. Immunol Allergy Clin North Am 29:285-293

33. Vanderbilt JN, Miesfeld R, Maler BA, Yamamoto KR 1987 Intracellular receptor concentration limits glucocorticoid-dependent enhancer activity. Mol Endocrinol 1:68-74
34. Daniel JA, Carroll JA, Keisler DH, Kojima CJ 2008 Evaluation of immune system function in neonatal pigs born vaginally or by cesarean section. Domest Anim Endocrinol 35:81-87

35. M'Rabet L, Vos AP, Boehm G, Garssen J 2008 Breast-feeding and its role in early development of the immune system in infants: consequences for health later in life. J Nutr 138:1782S-1790S

36. Blecha F, Kelley KW 1981 Effects of cold and weaning stressors on the antibodymediated immune response of pigs. J Anim Sci 53:439-447

37. de Groot J, van Milligen FJ, Moonen-Leusen BW, Thomas G, Koolhaas JM 1999 A single social defeat transiently suppresses the anti-viral immune response in mice. J Neuroimmunol 95:143-151

38. Meerlo P, Overkamp GJ, Koolhaas JM 1997 Behavioural and physiological consequences of a single social defeat in Roman high- and low-avoidance rats. Psychoneuroendocrinology 22:155-168 